\title{
CFD Analysis of Shrouded Diffuser Wind Turbine
}

\author{
L.Prabhu, S.Prakash, Praveen Aadithya, Yoga Vignesh, Sesha Rajakumaran
}

\begin{abstract}
The power in the wind is well known to be proportional to the cubic power of the wind velocity approaching a wind turbine. This means that even small amount of its acceleration gives large increase in the power output. Brimmed diffuser shrouds for small wind turbines are being used to accelerate the wind velocity in small wind regimes. The objective of the Paper is to analyze the flow characteristics of brimmed diffuser shroud and to optimize the physical dimensions. CFD analyses are carried out by varying its physical dimensions with the aim of achieving augmented velocity. The effect of flow parameters with the presence of diffuser is analyzed by comparing it with bare wind turbine. The physical dimensions of brimmed diffusers are the parameters considered in this study. The study has been carried with proposed splitted diffuser design. The power yield of the turbine for shifting speeds is gotten and analyzed.The CFD tool CFX would be used to anlayse the flow field around the diffuser. Performance of wind turbine under various operating conditions is generally obtained through an experimental testing and could be cost prohibitive. In this case the computational fluid dynamics analysis provides better results. The capability of using computational fluid dynamics is a test to determine its viability for determining its performance parameters.
\end{abstract}

Keywords:Wind Turbine, CFD, Brimmed diffuser shrouds

\section{INTRODUCTION}

A wind turbine is a device that converts the wind's kinetics energy into electrical energy. Wind vitality is mechanical vitality and the framework used to change the motor vitality of the breeze into mechanical vitality is called windmill. The term wind turbine is the updated version of the term windmill. As early as 200 B.C., mechanical energy was used for specific tasks including grinding grain and pumping water. Nowadays, the kinetic energy contained in the air can be converted into electricity via a generator. The intermittency of wind does not create problems when using wind power at low to moderate penetration level. It is more economically feasible than solar and bio-mass.

Improvements in wind turbine efficiency would lower the cost of wind power and thereby advance its suitability for investments in the energy market. At present, the most established machine for harvesting wind energy is the

Revised Manuscript Received on September 22, 2019

* Correspondence Author

L.Prabhu - Professor, Department of Mechanical Engineering,

Aarupadai Veedu Institute of Technology, Vinayaka Mission

Research Foundation, Deemed to be University, prabhu@ avit.ac.in

S.Prakash -Research Scholar, Department of Mechanical Engineering,

Aarupadai Veedu Institute of Technology, Vinayaka Mission Research Foundation, Deemed to be University Prakash.mech94@gmail.com

Praveen Aadithya, Yoga Vignesh \& Sesha Rajakumaran, UG Scholars, Aarupadai Veedu Institute of Technology, Vinayaka Mission'S Research Foundation the vast majority of the promising sustainable power source. The breeze vitality is right off the bat used to deliver

horizontal axis wind turbine (HAWT).The reduction of fossil fuel dependency is an important goal for both developed and developing countries. All these energy sources are limited and at the same time these energy sources create pollution problems. To accomplish this objective, the sustainable power source creation specifically world vitality age must be definitely expanded. That is the reason wind vitality is noticeable and it is one of the answers for the worldwide vitality issue. The breeze vitality is produced by utilizing wind turbines. Wind speed is viewed as expanded with the assistance of progression guideline.Connecting shafts, support bearings, the generator, plus other machinery; a tower; and ground-mounted electrical equipment. The turbine blades play very important role in the wind turbines. Blades are required to preserve an optimum cross-section for aerodynamic efficiency to generate the maximum torque to drive the generators.

Wind power generation is proportional to the wind speed cubed. In small scale wind turbine, diffuser is utilized to make weight drop after turn of sharp edges so high speed yield can be acquired. In wind turbine, fixed airfoil formed cutting edges are mounted on fixed shaft as stator and moving sharp edges are mounted on moving shaft. Along these lines, air encroached on fixed sharp edges so moving cutting edges are pivoting.

\section{SHROUDED DIFFUSER WIND TURBINE}

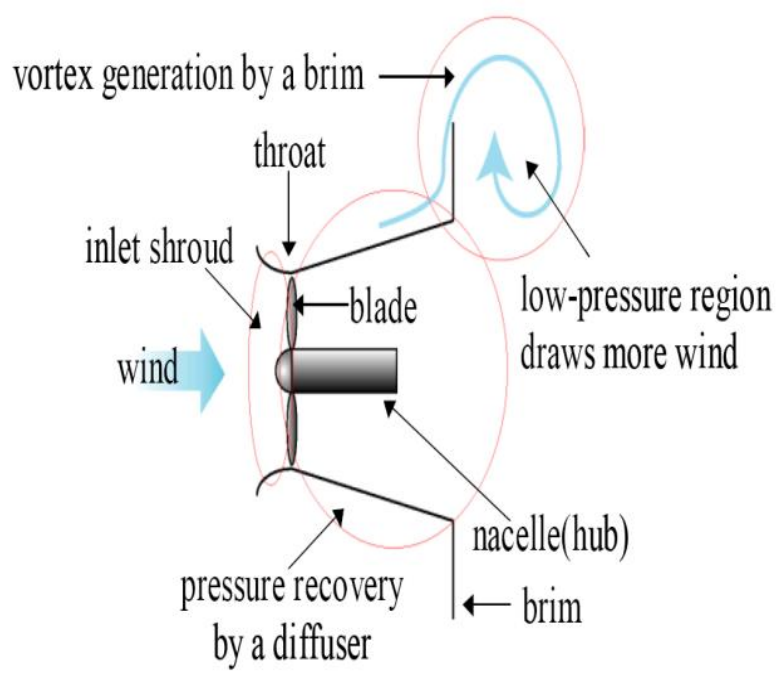

Published By: 


\section{CFD Analysis of Shrouded Diffuser Wind Turbine}

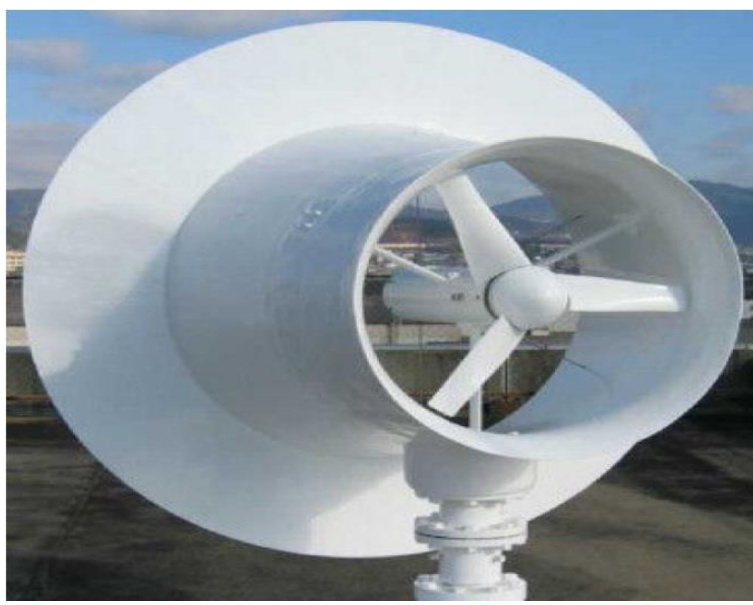

Fig 2.1 Shrouded diffuser Wind turbine

Such systems can increase the power of a Horizontal-Axis Wind Turbine by 2-5 times, for a given blade diameter and wind speed.

It is dependent upon very high rotational speeds during storms, thus their edges must be built thick enough to withstand the subsequent burdens, and alternators must have a method for keeping cool enough so they are not harmed by overheating. While controlling a dump load so as to back sharp edges off can help, some type of air-cooled warmth sink alongside stator curls might be expected to accomplish enough cooling.

Conventional wind turbines have continued to increase in size and height in recent years, with the main aim of generating more energy. However, their fundamental designs have not changed much. Today's wind turbines are still based on the physical principles of that of 18th century wind mills. Recent years have seen the development of innovative technologies that aim to improve the production of energy from wind turbines through the use of newer designs and technologies. A revolutionary breakthrough seen to be a major step in wind energy is found in the form of shrouded wind turbines that produce more energy than traditional wind turbines by more than $100 \%$.Shrouded wind turbines feature turbines that are housed in a ring-shaped lens that increase the speed of the rotor blades. It is based on the principles used on jet engines. Before the mid-20th century, planes were limited to having open propellers, but the development of the gas turbine engine paved the way for modern aircraft and the age of jet planes.

\section{MODELING OF GEOMETRY}

Modeling was done using Creo Parametric and exported in IGS format. The models of wind turbine have been shown in the following figures.

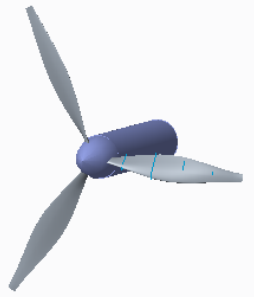

(a) Bare Wind turbine

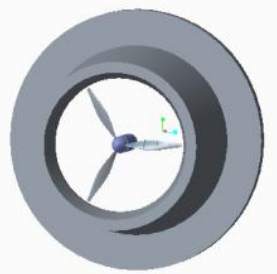

(b) Diffuser Wind turbine
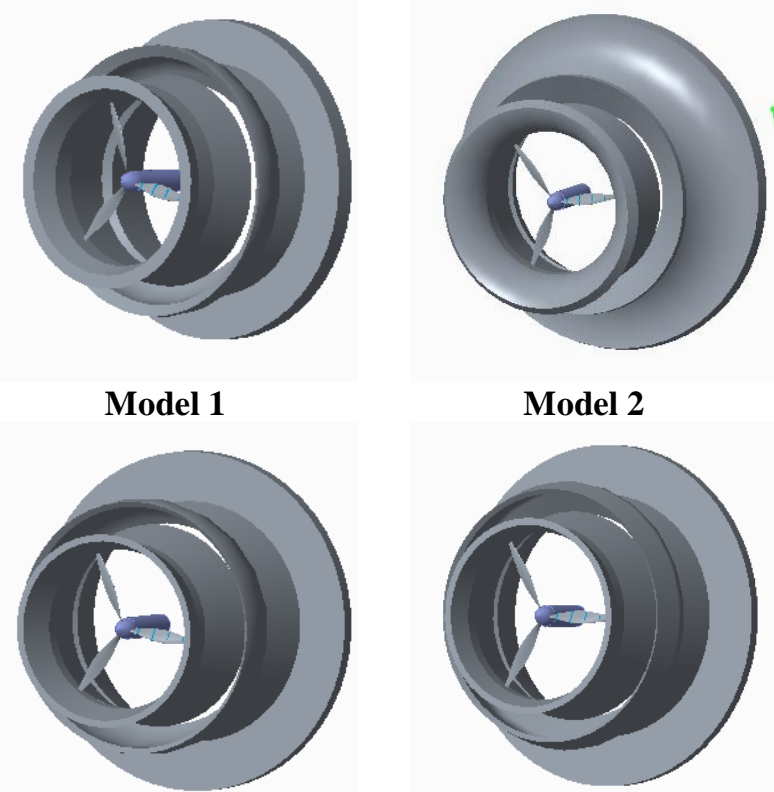

Model 2

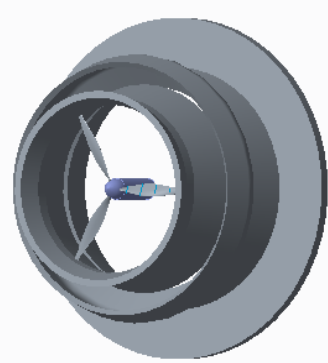

Model 4
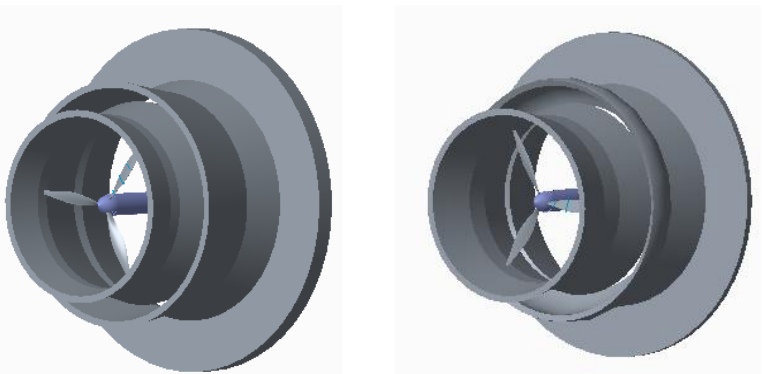

Model 6

Model 5

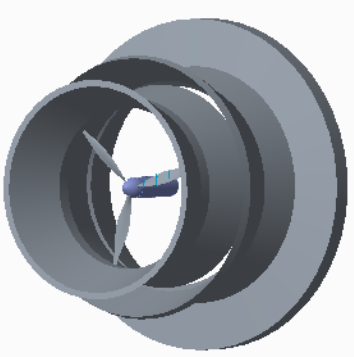

Model 7

Fig 3.1 Pro E Models of Wind Turbine

Mesh generation is the process by which spatial discretization of CFD model is accomplished. Meshing is based on tetrahedron element discretization.

The model is exported in IGES format and is used in ICEM- CFD tool. Surface and volume meshes were generated using this tool by defining the type of meshing element and mesh element size. 


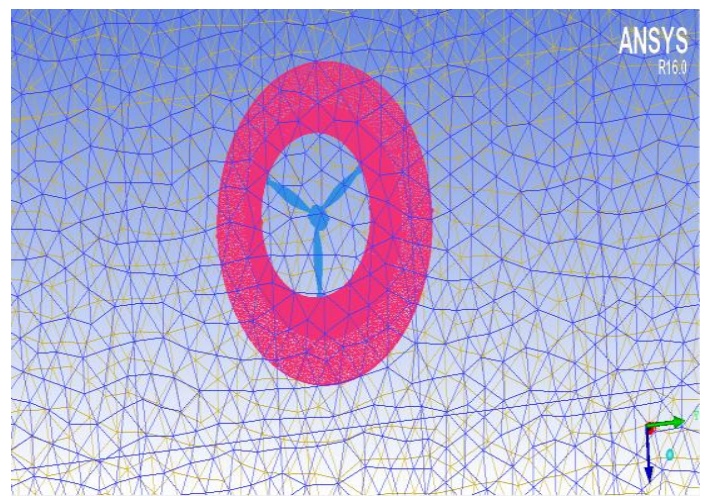

Fig 3.2 (a) Existing diffuser model

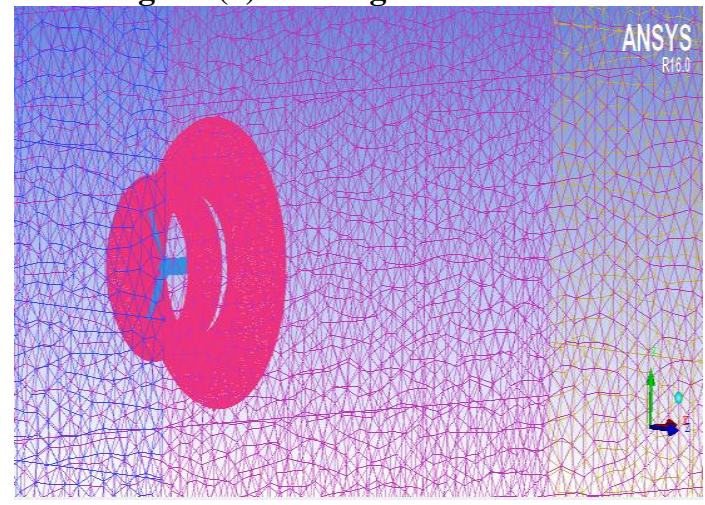

Fig 3.2 (b) Modified Diffuser model

Fig 3.2 Meshed Models

\section{RESULTS AND DISCUSSION}

\section{A.Velocity Distribution}

The figure 4.1 shows the velocity variation of bare and diffuser wind turbine. The results show that the velocity relatively increases at the turbine rotor of a diffuser wind turbine. The increase in velocity at the rotor is due to presence of convergent profile of inlet shroud. Further a significant increase in wake formation behind the diffuser has been observed which causes low pressure region behind the turbine. This low pressure region draws more air to strike the turbine rotor which in turn augments the torque.

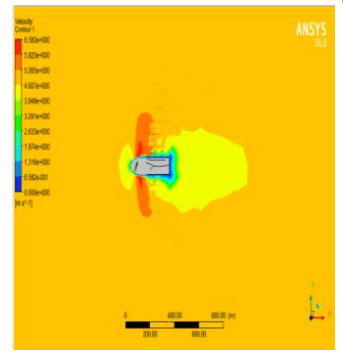

(a) Bare Wind turbine

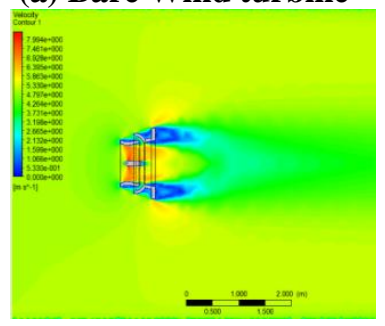

(c) Model 1

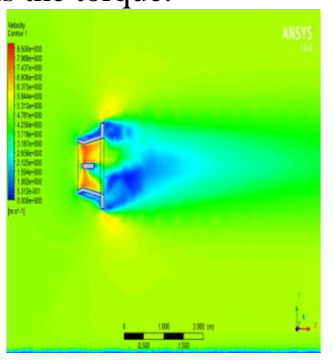

(b) Existing Model

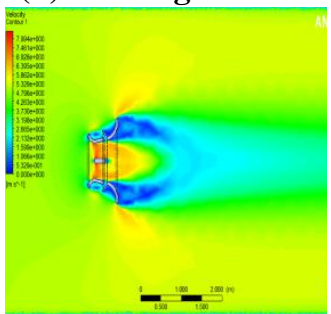

(d) Model 2

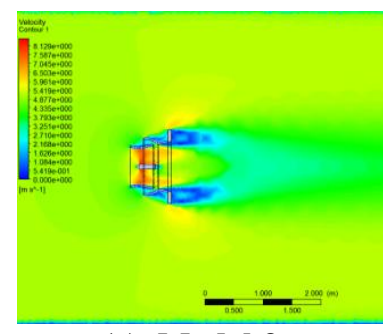

(e) Model 3

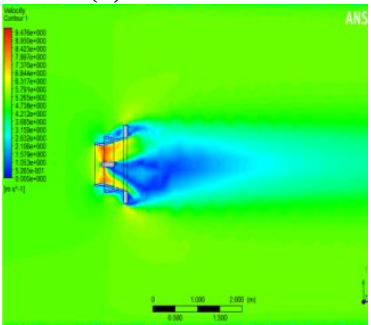

(g) Model 5

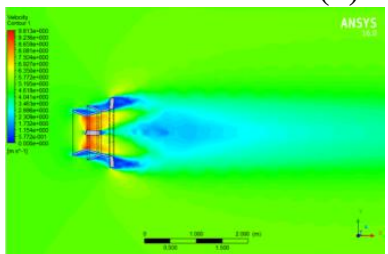

(i) Model 7

Fig 4.1 Velocity Distribution

The velocity variation for modified (splitted) diffuser models have been shown in fig. However, the velocity at the inlet shrouds of the models 1 and 2 are relatively lower than the existing model diffuser wind turbine the uniform velocity distribution is observed along the diffuser. The velocity distribution at the inlet shroud of the models 2 and 3 has marginally increased with models 1 and 2 maintaining the uniform velocity along the diffuser. The wake formation behind the diffusers of model 5 and 6 is higher causing higher mass flow of air at the inlet resulting in increased velocity and the wake formation is relatively higher for the model 7 causing further increase in velocity at the inlet shroud.

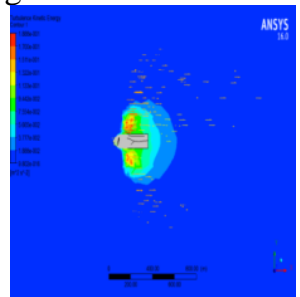

(a) Bare Wind turbine

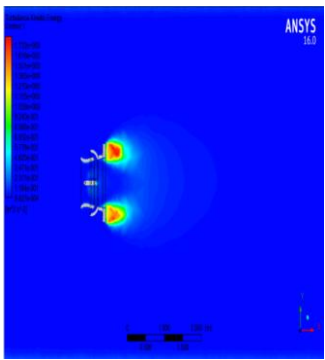

(c) Model 1

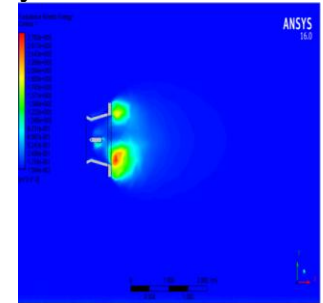

(b) Existing Model

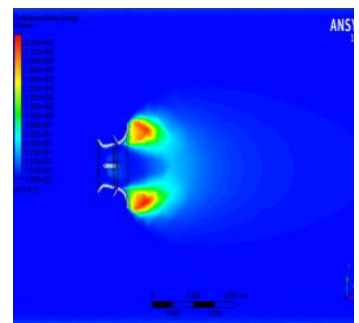

(d) Model 2

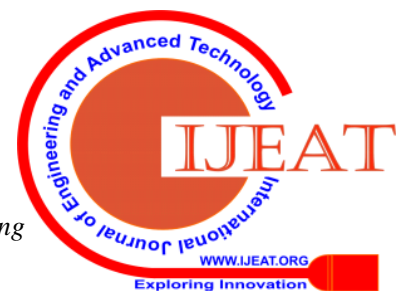




\section{CFD Analysis of Shrouded Diffuser Wind Turbine}

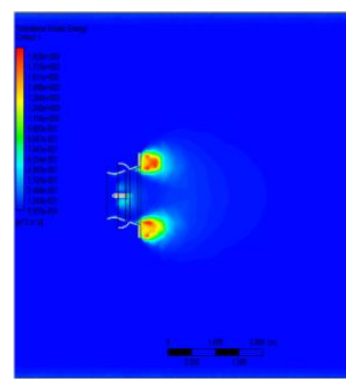

(e) Model 3

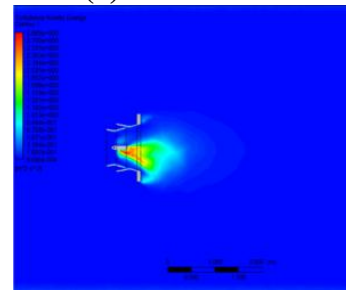

(g) Model 5

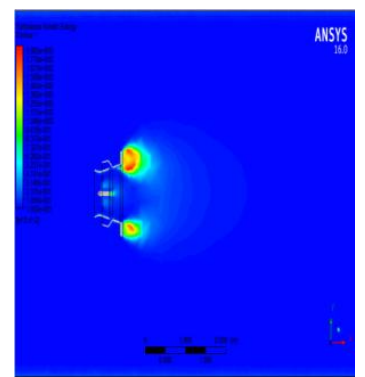

(f) Model 4

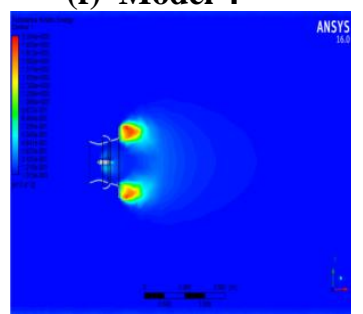

(h) Model 6

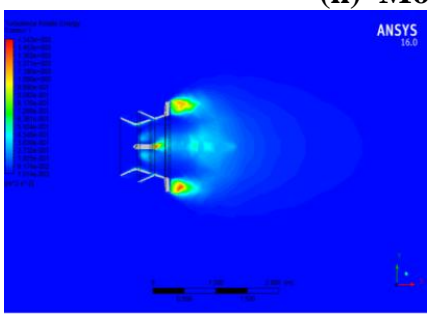

(i) Model 7

Fig 4.2 Turbulence kinetic energy variation B. TURBULENCE KINETIC ENERGY VARIATION

The fig. 4.2 shows turbulence kinetic energy variation along the wind turbine. Turbulence kinetic energy refers intensity of turbulence. Increased turbulence at the brim behind the existing model of diffuser of wind turbine has been observed which causes wake formation. The presence of wake region at the brim of splitted diffuser is observed and its magnitude is marginally lower for the models 1 and 2 and it is symmetric on either sides. The intensity of turbulence increases at the brim for the models 3 and 4 resulting in increased mass flow of air at the inlet shroud. The higher magnitude of turbulence is observed at the downstream of diffuser for the model 5 and exhibits asymmetric flow field. The higher turbulence at the diffuser brim of model 6 is observed where as symmetric wake region at the downstream and behind the diffuser brim for the model 7 cause increased mass flow is resulting in higher velocity at the inlet.

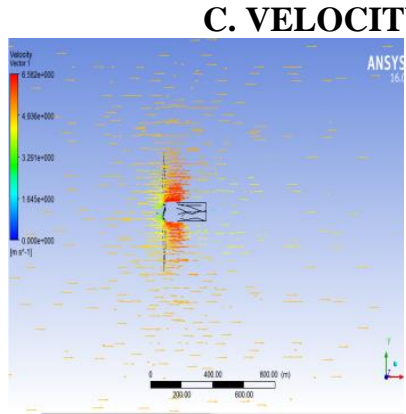

(a) Bare Wind turbine

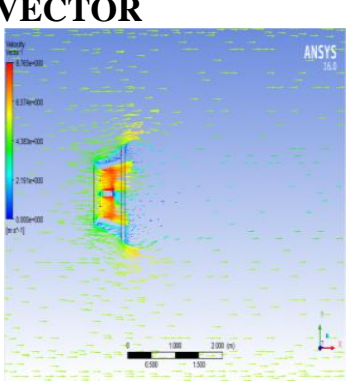

(b) Existing Model

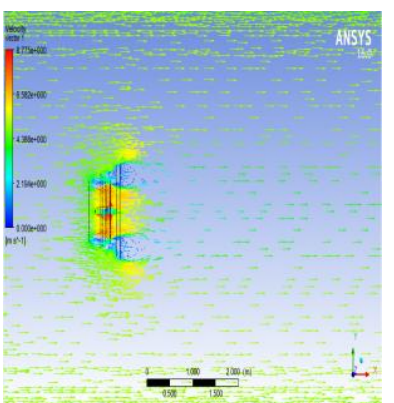

(c) Model 1

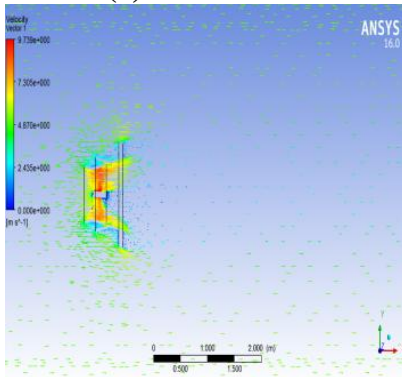

(e) Model 3

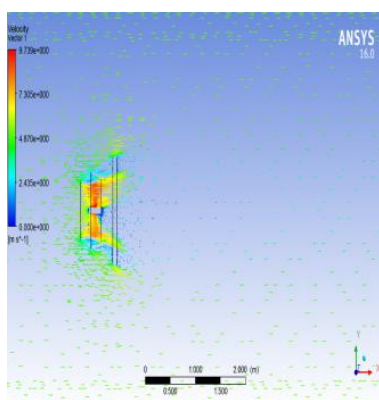

(g) Model 5

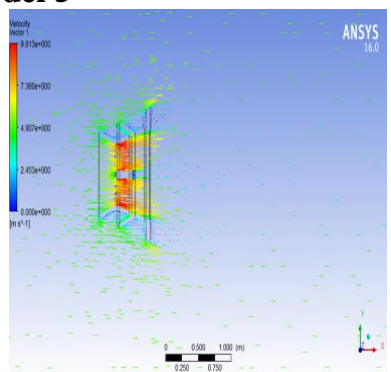

(i) Model 7

Fig.4.3 Velocity Vectors

The fig.4.3 shows the velocity vector around the wind turbine. The recirculating flow at brim of the diffuser wind turbine is observed which is causes turbulent flow field where as such flow field is not present in the base line model. In the modified diffuser model the two recirculation zones have been observed primary zone is at the splitted area and secondary zone is behind the diffuser brim which is higher in magnitude which causes turbulence.

\section{VELOCITY VARIATION AND OUTPUT POWER}

The average velocity obtained at the wind turbine rotor for various inlet velocity is given in following table 


\begin{tabular}{|c|c|c|c|c|c|}
\hline $\begin{array}{c}\text { S. } \\
\text { No }\end{array}$ & $\begin{array}{c}\text { Descripti } \\
\text { on }\end{array}$ & $\begin{array}{r}\text { Inlet } \\
\text { velocity } \\
3 \mathrm{~m} / \mathrm{s}\end{array}$ & $\begin{array}{r}\text { Inlet } \\
\text { velocity } \\
5 \mathrm{~m} / \mathrm{s}\end{array}$ & $\begin{array}{r}\text { Inlet } \\
\text { velocity } \\
8 \mathrm{~m} / \mathrm{s}\end{array}$ & $\begin{array}{c}\text { Inlet } \\
\text { velocity } \\
11 \\
\mathrm{~m} / \mathrm{s}\end{array}$ \\
\hline 1 & $\begin{array}{c}\text { Bare } \\
\text { turbine }\end{array}$ & 3.93 & 6.58 & $\begin{array}{c}10.4 \\
6\end{array}$ & $\begin{array}{c}14.3 \\
9\end{array}$ \\
\hline 2 & $\begin{array}{c}\text { Existing } \\
\text { Model }\end{array}$ & 5.21 & 8.77 & $\begin{array}{l}13.7 \\
1\end{array}$ & $\begin{array}{l}18.4 \\
7\end{array}$ \\
\hline 3 & Model 1 & 4.97 & 8.42 & $\begin{array}{l}13.2 \\
6\end{array}$ & $\begin{array}{l}18.2 \\
4\end{array}$ \\
\hline 4 & Model 2 & 4.92 & 8.42 & $\begin{array}{l}13.2 \\
0\end{array}$ & $\begin{array}{l}18.1 \\
9\end{array}$ \\
\hline 5 & Model 3 & 5.15 & 8.56 & $\begin{array}{l}13.2 \\
5\end{array}$ & $\begin{array}{l}18.3 \\
6\end{array}$ \\
\hline 6 & Model 4 & 5.35 & 8.98 & $\begin{array}{l}14.2 \\
9\end{array}$ & $\begin{array}{l}19.7 \\
1\end{array}$ \\
\hline 7 & Model 5 & 5.86 & 9.73 & $\begin{array}{l}15.6 \\
3\end{array}$ & $\begin{array}{l}21.4 \\
9\end{array}$ \\
\hline 8 & Model 6 & 5.33 & 9.13 & $\begin{array}{l}14.3 \\
3\end{array}$ & $\begin{array}{c}19.7 \\
0\end{array}$ \\
\hline 9 & Model 7 & 5.89 & 9.81 & $\begin{array}{l}16.2 \\
0\end{array}$ & $\begin{array}{l}22.5 \\
8\end{array}$ \\
\hline
\end{tabular}

The output power of wind turbine can be calculated by using the following equation

$$
P=\frac{1}{2} \rho A V^{\mathrm{a}} C_{\mathrm{p}}
$$

where,

$P=$ Output Power, W

$\rho=$ Density of air, $\mathrm{kg} / \mathrm{m}^{3}$

$\mathrm{A}=$ Area of blade, $\mathrm{m}^{2}$

$V=$ Velocity of air, $\mathrm{m} / \mathrm{s}$

$C_{\mathrm{p}}=$ Power coefficient

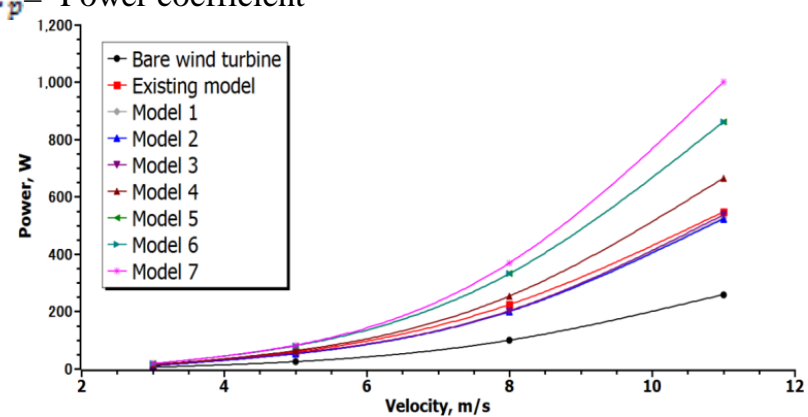

Fig. 4.4 Power output for various models

The output power obtained at wind turbine rotor for various models is shown in fig. 4.4. The output power for diffuser wind turbine is significantly high compared with bare wind turbine. While comparing the results for modified diffuser models the power output obtained from model 7 is relatively higher than the rest of the models.

\section{CONCLUSION}

The CFD analysis of wind turbine was carried and the following conclusion can be drawn

- The wind turbine with diffuser increases the velocity of air at the turbine rotor which can consequently increases the power of wind turbine.

- The presence of low pressure region at the primary as well as secondary zones of modified diffuser wind turbine increases the mass flow of air.

- The increase in velocity at the turbine rotor is marginal for the models 1,2 and 3 and is significant for the model 6 and 7.

- The average increase in power output for the model 7 is $58.19 \%$ when compared with existing diffuser wind turbine model.

\section{REFERENCES}

1.

Mahtabmurshed, Md. Yeasin Arafat, M. AbdurRazzak, (2016), "Analysis of air foils and design of blades for a low speed $250 \mathrm{kw}$ horizontal axis wind turbine suitable for coastal areas of Bangladesh"

2. S.Prabhakar, S.Prakash*, M.Saravana Kumar,K.Annamalai, JCHPS Special Issue 7: 2015, "Performance Analysis Of Ventilated Brake Disc For Its Effective Cooling” ISSN: 0974-2115

3. Aranake, Aniket C.; Lakshminarayan, Vinod K.; Duraisamy, Karthik, Mar 1, 2015, "Computational analysis of shrouded wind turbine configurations using a 3-dimensional RANS solver" Renewable Energy, Volume 75

4. Shailesh P. Patankar, Samir J. Deshmukh, Rucha R. Kolhekar, 2015,"Theoretical Analysis of Horizontal axis wind turbine For Low Wind Velocity", International journal of innovative and emerging research in engineering.

5. Abdelrahman M.A., Abdellatif O.E.,Moawed M.,Eliwa A (2015),"The CFD performance analysis for horizontal axis wind turbine with different blade shapes and tower effect" published in IEEE Journal.

6. Aniket C. Aranake, Vinod K. Lakshminarayan, KarthikDuraisamy 2015 "Computationalanalysis of shrouded wind turbine Configurations using a 3- dimensional RANS Solver"

7. Miguel Toledo Velázquez ,Marcelino Vega Del Carmen, Juan Abugaber Francis, Luis A. Moreno Pacheo, GuidlibaldoTolentinoEslava. (2014). "Design and Experimentation of a 1 MW Horizontal Axis Wind Turbine " Journal of Power and Energy Engineering,

8. RajuGovindharajan,

Dr.K.M.Paramasivam,

V.Vivek,

R.VishnuPriya,"Numerical investigation and design optimization of brimmed diffuser wind lens around a wind turbine "Published in The Eighth Asia-Pacific Conference On Wind Energy December 10-14,2013 Chennai, India.

\section{AUTHORS PROFILE}

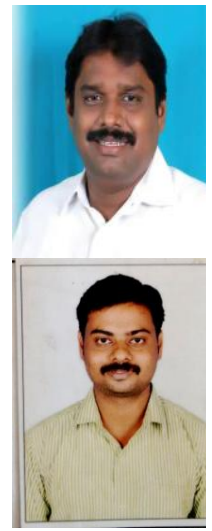

\section{L.Prabhu - Associate Professor}

Department of Mechanical Engineering

Aarupadai Veedu Institute of Technology

Vinayaka Mission Research Foundation

Deemed to be University

Prabhu@avit.ac.in

S.Prakash -Research Scholar

Department of Mechanical Engineering

Vinayaka Mission Research Foundation

Deemed to be University

Prakash.mech94@gmail.com 